\title{
KANDUNGAN ARSEN (As), BERBENTUK SUSPENSI DAN TERLARUT, DI PERAIRAN TELUK MANADO
}

\section{(The Concentration of Arsenic [As], in Forms of Suspended and Dissolved Arsenic, in Manado Bay Coastal Waters)}

\author{
Henry E. Lasut ${ }^{1}$, Nickson J. Kawung ${ }^{1}$, dan Markus T. Lasut ${ }^{2}$ \\ 1 Program Studi IImu Kelautan, Fakultas Perikanan dan IImu Kelautan, Universitas Sam \\ Ratulangi, Jl. Kampus UNSRAT Bahu, Manado 95115. \\ 2 Program Magister IImu Perairan, Fakultas Perikanan dan IImu Kelautan, Universitas Sam \\ Ratulangi, Jl. Kampus UNSRAT Bahu, Manado 95115. \\ *e-mail: lasuthenry@ymail.com
}

\begin{abstract}
A study on arsenic (As) contamination in Manado Bay Coastal Waters and its vicinity has been conducted with aims: 1) to measure As concentration in forms of suspended (As-S) and dissolved (As-T) arsenics; 2 ) to evaluate As concentration in the rivers of Bailang and Tondano which is loading to the bay; 3 ) to assess the status of water quality of the bay in relation to arsenic contamination. The results showed that: 1) concentration of As (in both forms) in Manado Bay was $<0.0005 \mathrm{ppm} ; 2$ ) concentration of As (in both forms) in the river of Bailang was $<0.0005$ $\mathrm{ppm}$; while in the river of Tondano, the concentration was $0.0012 \mathrm{ppm}$ and $0.0011 \mathrm{ppm}$ in forms of As-S and As-T, respectively; 3) water quality status of Manado Bay in relation to arsenic contamination was 'save', according to Indonesian regulation.
\end{abstract}

\begin{abstract}
Keywords: Arsenic (As), Manado Bay, Bailang River, Tondano River, Manado
Penelitian tentang kandungan arsen (As) di Perairan Teluk Manado dan sekitarnya telah dilakukan dengan tujuan untuk: 1) mengukur kandungan As yang terdapat dalam kolom air Teluk Manado, baik berbentuk suspensi maupun terlarut; 2) mengevaluasi kandungan As yang berasal dari Sungai Bailang dan S. Tondano yang masuk ke Perairan Teluk Manado, dan mengevaluasi perbedaan kandungan As antara kedua sungai tersebut; 3) menilai status pencemaran As di Perairan Teluk Manado berdasarkan Peraturan Pemerintah Republik Indonesia. Hasil penelitian menunjukkan bahwa : 1) kandungan As dalam kolom air Perairan Teluk Manado sebesar < $0,0005 \mathrm{ppm}$; 2) konsentrasi As dalam kolom air yang masuk ke Perairan Teluk Manado sebesar $<0,0005$ ppm untuk kedua bentuk As dari S. Bailang; 0,0012 ppm As bentuk suspensi dan 0,0011 ppm As bentuk terlarut dari S. Tondano; 3) status pencemaran As Perairan Teluk Manado masih dalam kondisi "aman".
\end{abstract}

Kata kunci: Arsen (As), Teluk Manado, Sungai Bailang, Sungai Tondano, Manado

\section{PENDAHULUAN}

Arsen (As) merupakan bahan kimia yang bersifat metaloid beracun yang ada dalam berbagai bentuk organik dan anorganik di alam. Metaloid adalah kelompok unsur kimia yang memiliki sifat antara logam dan nonlogam, sulit dibedakan dengan logam (Wikipedia, 2015). Di alam, bahan kimia ini terdapat di air, sedimen, dan biota (UNEP, 1988). Konsentrasinya di air berada sangat rendah. Dibandingkan dengan konsentrasi yang ada di dalam tubuh alga laut, konsentrasi di air berkisar 2000 - 5000 lebih rendah (UNEP, 1988). Sebagai contoh, yang terukur di perairan English Channel sebesar 2,6 ppb (Armstrong \& Harvey, 1950 dalam UNEP, 1988), dan di perairan Cape Basin (Atlantik) sebesar 1,3-1,7 ppb (Burton et al., 1980 dalam UNEP, 1988). Namun ada juga perairan yang mengalami peningkatan konsentrasi, khususnya di daerah estuari, misalnya di Carnon River sebesar 42 ppb di mana 
daerah ini merupakan daerah yang terhubung dengan kegiatan pertambangan (Klumpp dan Peterson, 1979 dalam UNEP, 1988).

Produksi dan penggunaan As di dalam kegiatan industri merupakan salah satu sumber pencemarannya di lingkungan. Industri-industri tersebut, antara lain, adalah industri pengolahan bijih logam, industri pestisida, industri pertambangan, industri pelapisan logam, dan proses penghilangan cat atau paint stripping (Istriani dan Pandebesie, 2014). Goulden (1952) dalam Sukar (2003) mengemukakan bahwa salah satu industri tambang yang melakukan pembakaran batubara dan pelelehan logam merupakan sumber utama pencemaran As di udara. Studi di inggris menunjukan bahwa kadar ratarata tahunan bahan kimia ini di daerah perkotaan sebagai total suspended particulate (TSP) berkisar antara 0,04 $\mu \mathrm{g} / \mathrm{m} 3$ dan $0,14 \mu \mathrm{g} / \mathrm{m} 3$. Arsen juga digunakan dalam berbagai keperluan, misalnya treatment penyakit syphilis (Rompas et al., 2009), di bidang pertanian untuk pestisida (Garelick dan Jones, 2008; WHO, 1996; WHO, 2012).

Kontaminasi As di lingkungan perairan laut memberikan dampak yang merugikan, terutama di daerah di mana kegiatan industri yang membuang limbahnya yang mengandung As jenis arsenous oxide/arsenite yang secara akut dan kronis beracun terhadap kehidupan perairan laut (UNEP, 1988). Selanjutnya, karena senyawa As dalam jumlah yang signifikan ditemukan pada organisme perairan laut; hal ini menimbulkan tanda tanya mengenai risikonya terhadap manusia manakala mengkonsumsi makanan dari laut.

Informasi tentang konsentrasi As di perairan (baik perairan sungai, pantai, maupun laut) di Provinsi Sulawesi Utara sulit ditemukan, kecuali yang dilakukan oleh Anonimus (2014) yang memantau perairan Sungai Buyat dan S. Totok. Hasil penelitian mereka untuk S. Buyat dan S. Totok menunjukkan bahwa konsentrasi As berbentuk suspensi, berturut-turut, sebesar $0,0061 \mathrm{ppm}$ dan 0,011 ppm; sedangkan untuk As berbentuk terlarut, berturut-turut, sebesar 0,005 ppm dan 0,011 ppm. Selain itu, dari hasil yang mereka peroleh, nampak bahwa konsentrasi As bentuk suspensi dan terlarut di S. Buyat memiliki konsentrasi yang berbeda.

Perairan Teluk Manado, di Provinsi Sulawesi Utara, merupakan perairan yang memiliki tingkat aktivitas manusia yang cukup tinggi, baik secara langsung maupun tidak, misalnya: penangkapan ikan, transportasi, dan pariwisata, serta aktivitas di daerah perkotaan. Kondisi perairan di teluk ini berpotensi terkontaminasi dengan bahan-bahan pencemar, karena buangan limbah dari kegiatan di perkotaan yang masuk ke perairan tersebut dalam status tercemar (Lasut et al., 2005), limbah tersebut tidak diolah terlebih dahulu (Lasut et al., 2008). Salah satu bahan pencemar tersebut adalah Arsen (As), yang sangat berbahaya bagi biota-biota yang hidup di perairan dan dapat membahayakan kesehatan manusia (Mukono, 2009). Menurut Lasut et al. (2005) dan (2008), limbah bahan pencemaran yang masuk ke Teluk Manado berasal dari daratan, yang pada umumnya, melalui sungaisungai. Enam sungai utama yang ada, yaitu: S. Bailang, S. Maasing, S. Tondano, S. Sario, dan S. Bahu, dan S. Malalayang.

Berhubungan dengan buangan bahan pencemar As, informasi tentang masuknya logam berat ini ke perairan Teluk Manado (baik dalam bentuk suspensi maupun bentuk terlarut) dari masing-masing sungai (S. Bailang dan $\mathrm{S}$. Tondano) belum pernah dilakukan analisis, sehingga kandungan As di perairan Teluk Manado belum ada informasi dari beberapa pustaka yang digunakan. Hal ini menjadi penting untuk diteliti dalam upaya untuk memantau dan melindungi perairan Teluk Manado dari ancaman pencemaran perairan. Berhubungan dengan hal tersebut, penelitian ini 


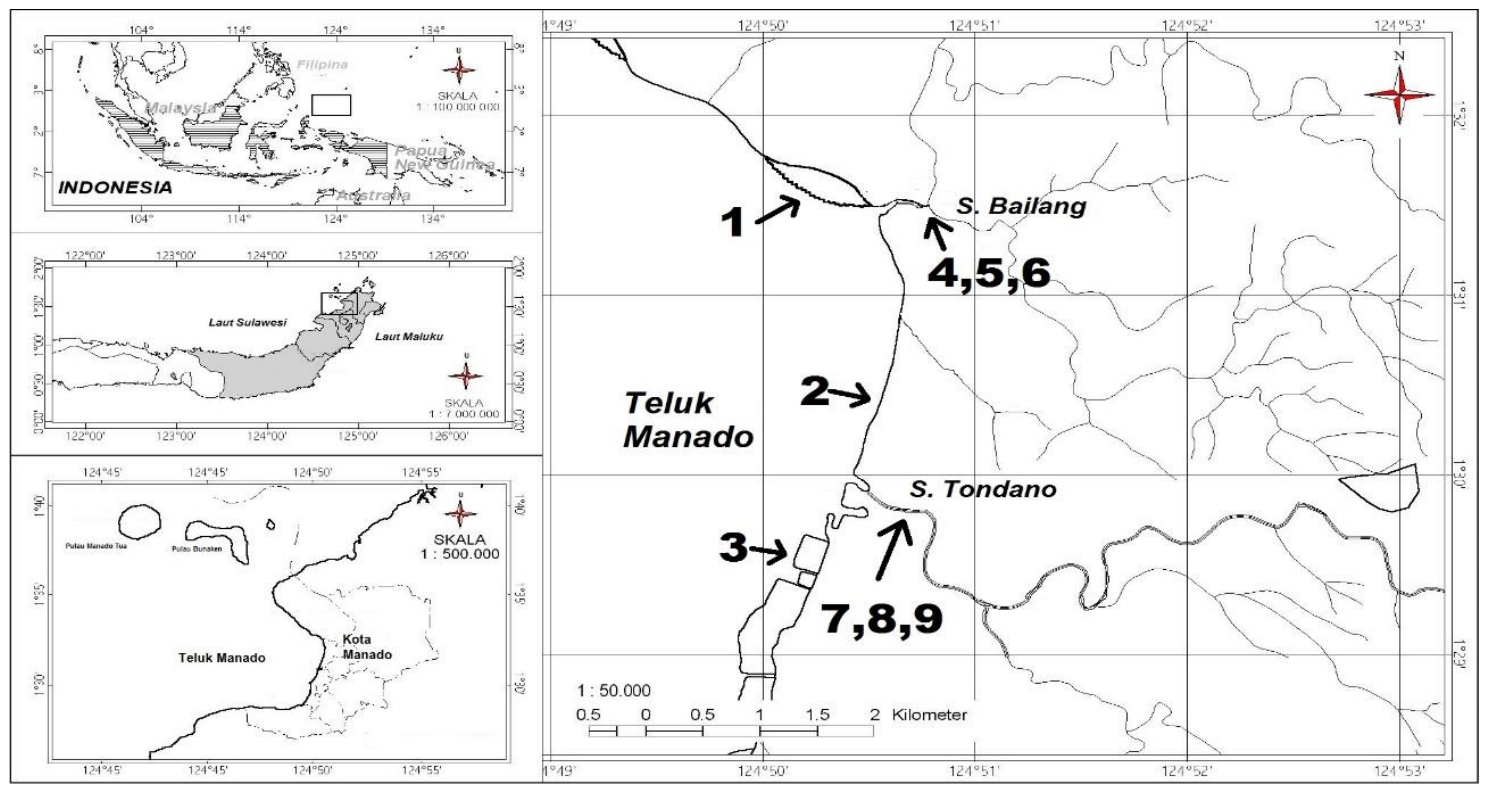

Gambar 1. Peta Lokasi Penelitian (1-9: titik pengambilan sampel [TS])

dilaksanakan di mana bertujuan untuk: 1) mengukur kandungan As yang terdapat dalam kolom air Teluk Manado, baik berbentuk suspensi maupun terlarut; 2) mengevaluasi kandungan As yang berasal dari Sungai Bailang dan S. Tondano yang masuk ke Perairan Teluk Manado, dan mengevaluasi perbedaan kandungan As antara kedua sungai tersebut; dan 3) menilai status pencemaran As di Perairan Teluk Manado berdasarkan Peraturan Pemerintah Republik Indonesia.

\section{METODE PENELITIAN Lokasi Pengambilan Sampel}

Air dijadikan sebagai sampel dalam penelitian ini, karena fokus penelitian adalah kolom air perairan. Pengambilan sampel (sampling) air dilakukan di 2 bagian perairan, yaitu: 1) Perairan Pantai Teluk Manado, dan 2) perairan sungai yang berhubungan dengan teluk tersebut. Pengambilan sampel yang berada di Perairan Pantai Teluk Manado dilakukan di 3 lokasi (Lokasi 1-3), dan yang berada di perairan sungai dilakukan di 2 lokasi (Sungai Bailang dan S. Tondano). Pada masing-masing lokasi, ditentukan 3 titik sampling (TS). Koordinat posisi TS secara geografis ditentukan menggunakan alat Global Positioning System (GPS) (Gambar 1).

Penentuan TS di aliran sungai dilakukan dengan cara menentukan bagian sungai yang belum bercampur dengan air asin, yang ditandai dengan rendahnya salinitas air (salinitas diukur menggunakan refraktosalinometer digital). Setelah menentukan bagian sungai tersebut, 3 (tiga) TS ditentukan, yaitu 2 (dua) TS pada bagian pinggir (kiri dan kanan), dan 1 (satu) TS pada bagian tengah. Metode pengambilan sampel air sesuai dengan Standar Nasional Indonesia (SNI) 6989.57-2008.

\section{Teknik Pengambilan Sampel}

Pengambilan sampel air laut di Perairan Teluk Manado dilakukan di bagian pinggiran pantai yang mudah dijangkau. Kolom air yang diambil adalah pada bagian permukaan (kirakira pada kedalaman $50 \mathrm{~cm}$ dari permukaan). Di masing-masing lokasi, ditentukan 3 TS, yaitu di bagian tengah, sisi kiri, dan sisi kanan. Jarak antara TS di bagian tengah dan TS di sisi kiri atau sisi kanan adalah sejauh $50 \mathrm{~m}$. Sampel air, di masing-masing lokasi, diambil secara komposit, yaitu mencampur sampel air dari 3 TS (bagian tengah, sisi 
kiri, dan sisi kanan). Pencatatan posisi koordinat geografi dilakukan pada TS bagian tengah. Pengambilan sampel air di ketiga TS dilakukan menggunakan wadah kecil (volume 1,800 ml); kemudian ketiga sampel air dalam wadah kecil dicampur (komposit) secara merata (dengan melakukan pengadukan secukupnya) di dalam wadah besar (volume 5,400 ml). Sampel air sebanyak $100 \mathrm{ml}$ diambil dari wadah besar tersebut dengan menggunakan botol kaca berpenutup (volume $100 \mathrm{ml}$ ), yang telah disterilkan.

Pengambilan sampel air sungai dilakukan secara langsung menggunakan wadah besar (volume $5,400 \mathrm{ml}$ ). Sampel air sebanyak $100 \mathrm{ml}$ diambil dari wadah besar tersebut dengan menggunakan botol kaca berpenutup (volume $100 \mathrm{ml}$ ), yang telah disterilkan. Selama kegiatan sampling, botol yang telah berisi sampel dan ditutup rapat diletakkan dalam kotak penyimpanan sementara yang berisi gel pendingin (cool box) sebelum dianalisis di laboratorium.

\section{Pengukuran Arsen}

Pengukuran kandungan As dalam sampel dilakukan di Laboratorium WLN Manado, menurut panduan American Public Health Association dengan nomor APHA-3120-B (2012). Penentuan kandungan As (bentuk suspensi dan terlarut) menggunakan alat Inductively Coupled PlasmaEmmission Spectrofotometer (ICP. OES), yang memiliki batas deteksi sebesar 0,0005 ppm. Secara ringkas, analisis laboratorium untuk pengukuran As dalam sampel air adalah sebagai berikut:

\section{a. Persiapan Sampel}

Oleh karena 2 (dua) bentuk sampel air yang diukur (suspensi dan terlarut), maka sampel disiapkan dengan cara sebagai berikut:

1. Sampel air untuk analisis As berbentuk suspensi (As-S). Dalam analisis sampel dilakukan proses digestion dengan cara sebagai berikut:

- menuang $50 \mathrm{ml}$ sampel (yang telah diawet dengn $\mathrm{HNO}_{3}$ pekat hingga $\mathrm{pH}<2$ ) ke dalam piala gelas $100 \mathrm{~mL}$ kemudian tambahkan $2.5 \mathrm{ml} \mathrm{HNO}_{3}$ pekat. Tutup piala gelas tersebut dengan kaca arloji dan panaskan pada suhu $85 \pm 5^{\circ} \mathrm{C}$ selama 2 jam.

- menurunkan piala gelas dalam pemanas. Bila kaca arloji penutup dan dinding piala gelas dengan air ultra pure. Tambahkan $1.5 \mathrm{ml} \mathrm{HNO}_{3}$ pekat kemudian panaskan kembali dengan suhu $85 \pm 5 \stackrel{\circ}{\circ} \mathrm{C}$ selama 15 menit.

- mendinginkan sampel tersebut dan saring dengan kertas saring $0.45 \mu$ ke dalam labu ukur 100 $\mathrm{mL}$ dan himpitkan hingga tanda batas. Sampel siap untuk dianalisis.

- membuat blank digestion pada awal, setiap kelipatan 15 sampel dan air digest.

2. Persiapan sampel air untuk analisis As terlarut (As-T). Analisis sampel dilakukan dengan cara sebagai berikut:

- menyaring sampel menggunakan kertas saring 0.45 $\mu$, kemudian ditambahkan pengawet $\mathrm{HNO}_{3}$ pekat hingga $\mathrm{pH}<2$ dan dihomogenkan. Sampel siap untuk dianalisis.

- membuat blank penyaringan pada awal, setiap kelipatan 15 sampel dan air penyaringan.

\section{b. Pengukuran Sampel}

Dengan menggunakan alat ICPOES, konsentrasi As dihasilkan secara digital dan dibaca langsung pada alat tersebut. 
Tabel 1. Konsentrasi Arsen berbentuk suspensi (As-S) dan terlarut (As-T) di Perairan Teluk Manado.

\begin{tabular}{|c|c|c|c|c|c|}
\hline \multirow{2}{*}{$\begin{array}{l}\text { Lokasi } \\
\text { Sampling }\end{array}$} & \multirow{2}{*}{$\begin{array}{c}\text { Salinitas } \\
\text { (ppt) }\end{array}$} & \multicolumn{2}{|c|}{ Koordinat TS } & \multirow{2}{*}{$\begin{array}{l}\text { As-S } \\
\text { (ppm) }\end{array}$} & \multirow{2}{*}{$\begin{array}{l}\text { As-T } \\
\text { (ppm) }\end{array}$} \\
\hline & & LU & BT & & \\
\hline 1 & 34 & 1031'29.6" & $124^{\circ} 50^{\prime} 16.6^{\prime \prime}$ & $<0,0005$ & $<0,0005$ \\
\hline 2 & 35 & 1029'13.7"' & $124^{\circ} 50^{\prime} 2.5^{\prime \prime}$ & $<0,0005$ & $<0,0005$ \\
\hline 3 & 31 & $1^{\circ} 27^{\prime} 45.8 "$ & $\begin{array}{r}\text { 12449'16.6”' } \\
\text { Rerata }\end{array}$ & $\begin{array}{l}<0,0005 \\
<0,0005\end{array}$ & $\begin{array}{l}<0,0005 \\
<0,0005\end{array}$ \\
\hline
\end{tabular}

Keterangan: LU: Lintang Utara; BT: Bujur Timur

Tabel 2. Konsentrasi Arsen berbentuk suspensi (As-S) terlarut (As-T) di Sungai Bailang dan Sungai Tondano.

\begin{tabular}{|c|c|c|c|c|c|}
\hline \multirow{2}{*}{$\begin{array}{c}\text { Titik Sampling } \\
\text { (TS) }\end{array}$} & \multirow{2}{*}{$\begin{array}{l}\text { Salitas } \\
\text { (ppt) }\end{array}$} & \multicolumn{2}{|c|}{ Koordinat TS } & \multirow{2}{*}{$\begin{array}{l}\text { As-S } \\
\text { (ppm) }\end{array}$} & \multirow{2}{*}{$\begin{array}{l}\text { As-T } \\
\text { (ppm) }\end{array}$} \\
\hline & & LU & $\mathrm{BT}$ & & \\
\hline \multicolumn{6}{|c|}{ A. Sungai Bailang } \\
\hline 4 & 1 & \multirow{4}{*}{$1^{\circ} 31^{\prime} 44.2 "$} & \multirow[b]{2}{*}{$124^{\circ} 50^{\prime} 51.4^{\prime \prime}$} & $<0,0005$ & $<0,0005$ \\
\hline 5 & 1 & & & $<0,0005$ & $<0,0005$ \\
\hline \multirow[t]{2}{*}{6} & 1 & & & $<0,0005$ & $<0,0005$ \\
\hline & & & Rerata & $<0,0005$ & $<0,0005$ \\
\hline \multicolumn{6}{|c|}{ B. Sungai Tondano } \\
\hline 7 & 1 & \multirow{4}{*}{$1^{\circ} 29^{\prime} 35.1^{\prime \prime}$} & \multirow{3}{*}{$124^{\circ} 50^{\prime} 49.1^{\prime \prime}$} & 0,0010 & 0,0010 \\
\hline 8 & 1 & & & $<0,0005$ & $<0,0005$ \\
\hline \multirow[t]{2}{*}{9} & 1 & & & 0,0014 & 0,0011 \\
\hline & & & Rerata & 0,0012 & 0,0011 \\
\hline
\end{tabular}

Keterangan: LU: Lintang Utara; BT: Bujur Timur

\section{Analisis Data}

Data hasil pengukuran kandungan As dianalisis menggunakan Statistika sederhana (simple Statistica) untuk menghitung rerata. Kemudian data disajikan secara deskriptif dalam bentuk tabel.

\section{HASIL DAN PEMBAHASAN} Kandungan Arsen (As) di Perairan Teluk Manado

Perairan Teluk Manado tergolong perairan yang memiliki aktivitas yang tinggi mulai dari transportasi laut sampai pada kegiatan pertokoan di garis pantai. Adanya kegiatan tersebut bukan tidak mungkin memberikan dampak bagi kondisi kualitas air di perairan tersebut. Faktor yang mempengaruhi kondisi kualitas air, antara lain, yaitu komponen kimia yang ada dalam air yang dapat bersifat racun bagi biota yang hidup di dalamnya. Bahan kimia yang mempengaruhi kualitas air tersebut, yaitu arsen (As) di mana secara alami bersumber dari alam itu sendiri, dan juga dari aktivitas manusia.

Hasil pengukuran arsen di Perairan Teluk Manado baik dalam bentuk suspensi (As-S) maupun terlarut (As-T) pada 3 lokasi pengambilan sampel ditunjukan pada Tabel 1.

Nampak, baik As berbentuk suspensi (As-S) maupun terlarut (As-T), berada dalam konsentrasi sangat rendah (lebih rendah dari batas deteksi alat, yaitu $<0,0005 \mathrm{ppm}$ ). Hasil ini juga memperlihatkan, bahwa konsentrasi As antara bentuk tersuspensi (As-S) dan terlarut (As-T) tidak berbeda. Dengan demikian, kandungan As di Perairan 
Teluk Manado adalah sebesar $<0,0005$ ppm.

Di alam, konsentrasi As yang tinggi, umumnya, ditemukan di air sekitar daerah geothermal, yang dapat mencapai 2,6 - 50 ppm (Herdianira dan Priadi, 2008). Konsentrasi yang rendah ditemukan pada air tanah (aquifer), seperti yang ditemukan di daerah permukiman di pesisir Pulau Jawa, yaitu berkisar 0,59 - 15,19 ppb (Suryono et al., 2008). Hal ini menunjukkan bahwa As berasal dari berbagai sumber di alam.

dalam $\begin{gathered}\text { Arsen di perairan pantai berada } \\ \text { konsentrasi bervariasi. }\end{gathered}$ Keberadaannya berasal dari berbagai sumber (non-point source), misalnya dari bebatuan alamiah (Istarani dan Pandebesie, 2014) dan dari pembuangan limbah pertambangan (Santosa, 2013). Di sedimen buangan tailing di Teluk Buyat, As diukur sebesar 550-660 ppm (Walhi, 2007 dalam llyas et al., 2009).

\section{Masukan Arsen (As) dari S. Tondano dan S. Bailang ke Teluk Manado}

Tabel 2 menampilkan masukan

(input) As, baik dalam bentuk tersuspensi (As-S) maupun terlarut (AsT), dari S. Bailang dan S. Tondano ke Perairan Teluk Manado pada saat pengambilan sampel. Nampak, konsentrasi kedua bentuk As pada sampel air di S. Bailang (TS-4, 5, dan 6) sama besarnya, yaitu sebesar $<0,0005$ ppm; sedangkan konsentrasi As di S. Tondano (TS-7, 8, dan 9), menunjukkan variasi, baik variasi antara kedua bentuk As maupun antara titik sampling (TS). Di S. Tondano, konsentrasi As berbentuk suspensi (As-S) dan terlarut (As-T) tertinggi ditemukan pada TS-9, yaitu, berturut-turut, sebesar 0,0014 ppm dan 0,0011 ppm; dan rerata konsentrasi As berbentuk suspensi (As-S) dan terlarut (As-T), berturut-turut, sebesar 0,0012 ppm dan 0,0011 ppm.

Konsentrasi As berbentuk suspensi (As-S) di S. Tondano tertinggi terdapat pada TS-7 dan 9. Tingginya konsentrasi As pada kedua titik tersebut disebabkan karena titik-titik tersebut berada di bagian tepi sungai yang berhubungan langsung dengan daerah yang diduga merupakan sumber dari As. Hal yang sama juga terjadi pada konsentrasi As terlarut di mana pada kedua titik tersebut konsentrasinya lebih tinggi dibandingkan dengan TS-8. Hal ini disebabkan karena massa air di TS-8 telah mengalami percampuran sehingga konsentrasi As menurun.

Perbedaan konsentrasi antara As berbentuk suspensi (As-S) dan terlarut (As-T) nampak pada sampel air dari sungai. Konsentrasi As berbentuk suspensi lebih tinggi dari terlarut. Di TS9, perbedaan konsentrasi dari kedua bentuk As tersebut sebesar 0,0003 ppm.

Secara alamiah, apabila tidak ada sumber pencemar (point-source), As di perairan sungai berada pada konsentrasi yang rendah. $\mathrm{Hal}$ ini ditunjukkan dari hasil penelitian saat ini (Tabel 2). Tingkatan yang sama juga ditunjukkan di perairan Sungai Pangkajene, Kabaten Pankep, di mana As terukur sebesar 0,03366 ppm (Bahar et al., 2016).

Keberadaan As di perairan sungai dapat berasal dari penggunaan pestisida (insektisida dan fungisida) di lahan pertanian. Contoh pestisida yang mengandung As, yaitu: bermerek Dursban 200 EC, Antracol 70 WP, Bamex, Reagen 50 SC, Curacron, Prevathon 50 SC, Agrimec 18 EC, Decis 2,5 EC, dan Dithane M-4/Detazeb 80 W (Fikri et al., 2012). Kegiatan pertambangan emas rakyat skala kecil juga dianggap sebagai sumber As di perairan sekitarnya, di mana As tersebut berasal dari bebatuan yang diolah untuk mendapatkan emas (Harijoko et al., 2010). 
Tabel 3. Status pencemaran perairan sungai dan Teluk Manado terhadap bahan kimia Arsen

\begin{tabular}{|c|c|c|c|c|c|c|}
\hline \multirow[t]{2}{*}{ Perairan } & \multirow[t]{2}{*}{ Lokasi } & \multicolumn{2}{|c|}{ Koordinat TS } & \multirow{2}{*}{$\begin{array}{l}\text { Baku } \\
\text { Mutu } \\
\text { (ppm) }\end{array}$} & \multirow{2}{*}{$\begin{array}{c}\begin{array}{c}\text { As-T* } \\
\text { (ppm) }\end{array} \\
\text { Hasil } \\
\text { Penelitian }\end{array}$} & \multirow[t]{2}{*}{ Status } \\
\hline & & LU & BT & & & \\
\hline Teluk & 1 & 1031'29.6" & $124^{\circ} 50^{\prime} 16.6^{\prime \prime}$ & $0,012^{a}$ & $<0,0005$ & Aman \\
\hline Manado & $\begin{array}{l}2 \\
3\end{array}$ & $\begin{array}{l}1^{\circ} 29^{\prime} 13.7^{\prime \prime} \\
1^{\circ} 27^{\prime} 45.8 "\end{array}$ & $\begin{array}{c}124^{\circ} 50^{\prime} 2.5^{\prime \prime} \\
124^{\circ} 49^{\prime} 16.6^{\prime \prime}\end{array}$ & $0,025^{b}$ & $\begin{array}{l}<0,0005 \\
<0,0005\end{array}$ & $\begin{array}{l}\text { Aman } \\
\text { Aman }\end{array}$ \\
\hline \multicolumn{2}{|c|}{$\begin{array}{c}\text { Sungai Bailang } \\
\text { (TS 4-6) }\end{array}$} & $1^{\circ} 31^{\prime} 44.2 "$ & $124^{\circ} 50^{\prime} 51.4^{\prime \prime}$ & $\begin{array}{c}0,05^{c} \\
1^{d}\end{array}$ & $<0,0005$ & Aman \\
\hline \multicolumn{2}{|c|}{$\begin{array}{c}\text { Sungai Tondano } \\
\text { (TS 7-9) }\end{array}$} & $1^{\circ} 29^{\prime} 35.1^{\prime \prime}$ & $124^{\circ} 50^{\prime} 49.1^{\prime \prime}$ & $\begin{array}{l}1^{e} \\
1^{f}\end{array}$ & 0,0011 & Aman \\
\hline
\end{tabular}

Keterangan:

a Kepmen LH No. 51/2004, Baku Mutu Air Laut Untuk Biota Laut;

b Kepmen LH No. 51/2004, Baku Mutu Air Laut Untuk Wisata Bahari;

c PP No. 82/2001, Kelas 1; d PP No. 82/2001, Kelas 2; e PP No. 82/2001, Kelas

$3 ;{ }^{\dagger}$ PP No. 82/2001, Kelas $4{ }^{*}$ As-T: Arsen bentuk terlarut

\section{Status Pencemaran Arsen (As) di Teluk Manado}

Status pencemaran perairan sungai (S. Bailang dan S. Tondano) dan Teluk Manado terhadap bahan kimia As ditampilkan dalam Tabel 3. Parameter yang digunakan untuk menentukan status pencemaran adalah As berbentuk terlarut (As-T). Hasil pengukuran menunjukkan bahwa kondisi Perairan Teluk Manado, S. Bailang, dan S. Tondano masih "aman" (tidak tercemar) terhadap bahan pencemar As. Untuk Perairan Teluk Manado, kondisi perairan tersebut memenuhi baku mutu untuk biota laut dan wisata bahari. Untuk perairan sungai, kondisi S. Bailang dan $\mathrm{S}$. Tondano memenuhi baku mutu untuk semua kelas peruntukan air.

\section{KESIMPULAN}

Beberapa hal dapat disimpulkan dalam penelitian ini, yaitu:

1. Kandungan As dalam kolom air Perairan Teluk Manado, baik berbentuk suspensi maupun terlarut sebesar < 0,0005 ppm.

2. Konsentrasi As (bentuk suspensi dan terlarut) dalam kolom air yang masuk ke Perairan Teluk Manado pada saat pengamatan yaitu sebesar < 0,0005 ppm untuk kedua bentuk As dari S. Bailang; 0,0012 ppm As bentuk suspensi dan 0,0011 ppm As bentuk terlarut dari $\mathrm{S}$. Tondano.

3. Status pencemaran As Perairan Teluk Manado masih berada dalam kondisi "aman".

\section{DAFTAR PUSTAKA}

Anonimus. 2014. Kegiatan penelitian dampak arsen pada masyarakat buyat. Laporan Akhir. Kerjasama antara Yayasan Pembangunan Berkelanjutan Sulawesi Utara (YPBSU) dan Fakultas Perikanan dan IImu Kelautan Unsrat. Fakultas Perikanan dan IImu kelautan Unsrat.

Bahar, S.N., Daud, A., Indar. 2016. Risiko paparan arsen pada masyarakat sekitar Sungai Pangkajene, Kecamatan Bungoro, Kabupaten Pangkep. Retrieved Februari 10, 2016, From http://repository.unhas. ac.id/handle/123456789/6477. 
Fikri, E., Setiani, O., Nurjazuli. 2012. Hubungan paparan pestisida dengan kandungan Arsen (As) dalam urin dan kejadian anemia (studi: pada petani penyemprot pestisida di Kabupaten Brebes). Retrieved Februari 10, 2016, From

http://ejournal.undip.ac.id/index. php/jkli/article/view/4138.

Garelick, H., Jones. H. 2008. Reviews of Environmental Contamination and Toxicology, Arsenic Pollution and Remediation: An International Perspective. Springer. 194 hal.

Harijoko, A., H, T.M., Saputra, R., Warmada, I.W., Stijadji, L.D., Imai, A., Watanabe, K. 2010. Mercury and arsenic contamination from small scale gold mining activities at Selogiri Area, Central Java, Indonesia. Retrieved Februari 10, 2016, From http://jurnal.ugm.ac.id/jag/ article/view/7235.

Herdianita, N.R,. Priadi, B. 2008. Arsenic and Mercury Concentrations at Several Geothermal System in West Java, Indonesia. Retrieved Februari, 10, 2016, From http://journals.itb.ac.id/index.php /imfs/article/view/28. Human Services Public Health Service. 499 hal.

Ilyas, M., Sudaryanto, A., Anantasena, Y., Takahashi, D., Tanabe, S. 2009. Is arsenic a potential threat for human health in Indonesia. Inorganic Arsenic Coumpounds. Twelfth Edition. Durham, National Institute of Enviromental Health Science. Retrieved Februari 10, 2016, From https://www.terrapub.co. ip/ onlineproceedings/ec/02/pdf/ ERA21.pdf.

Istarani, F., Pandebesie. E.S. 2014. Studi dampak arsen (As) dan kadmium (Cd) terhadap penurunan kualitas lingkungan. Jurnal Teknik Pomits, 3 (1): D53-D58.

Lasut, M.T., Jensen, K.R., Arai, T., Miyazaki, N. 2005. An assessment of water quality along the rivers loading to the Manado Bay, North Sulawesi, Indonesia. Coastal Marine Science 29 (2): 124-132.

Lasut, M.T., Jensen, K.R., Shivakoti, G. 2008. Analysis of constraints and potentials for wastewater management in the coastal city of Manado, North Sulawesi, Indonesia. Journal of Environmental Management 88: 1141-1150.

Mukono, H.J. 2009. Arsen (As), Dampak Terhadap Kesehatan dan Penanggulangannya. Retrie-ved November 12, 2014, From http://mukono.blog.unair. ac.id/2009/09/.

Rompas, R.M., Rumampuk, N.D.C., Rompas, R.J. 2009. Oseanografi Kimia. Penerbit Sekertariat Dewan Kelautan Indonesia.

Santosa, R.W. 2013. Dampak pencemaran lingkungan laut oleh perusahaan pertambangan terhadap nelayan tradisional. Retrieved Februari 10, 2016, From http://ejournal.unsrat.ac.id/ index.php/administratum/article/ view/3017.

Sukar. 2003. Sumber dan Terjadinya Arsen di Lingkungan (Review). Jurnal Ekologi Kesehatan. 2003, 2, 232-238.

Suryono, Ch.A., Sabdono, A., Rochaddi, B., Susanti, B.T. 2008. Arsenic contamination of the coastal aquifers in the North Coast of Java, Indonesia. Retrieved Februari 10, 2016, From http://ejournal.undip.ac.id /index.php/ijms/article/view/521. 
UNEP. 1988. GESAMP: Arsenic, mercury and selenium in the marine environment. UNEP Regional Seas Reports and Studies No. 92, GESAMP Reports and Studies No. 28. Regional Seas. 172 hal.

WHO. 1996. Guidelines for DrinkingWater Quality. Vol 2, 2nd ed. Geneva, World Health Organization.

WHO. 2012. Arsenic. Fact Sheet N`372. Retrieved November 12, 2014, from http://www.who.int/ mediacentre/factsheets/fs372/en

Wikipedia. 2015. Metaloid. http://id. wikipedia.org/wiki/Metaloid. Diakses pada 17 Mei 2015. 